\title{
FACTOR V LEIDEN MUTATION AND ITS IMPACT ON PREGNANCY COMPLICATIONS
}

\author{
L'ubica Hammerová ${ }^{1}$, Ján Chabada ${ }^{1}$,Juraj Drobnýr, Angelika Bátorová2
}

Comenius University, Faculty of Medicine University Hospital, Bratislava, Slovakia: 1st Department of Gynaecology and Obstetrics $^{1}$

The National Haemophilia Centre, Institute of Haematology and Blood Transfusion, University Hospital, Bratislava, Slovakia $^{2}$

Summary: Objective: The aim of this prospective study was to find the association between the factor V Leiden mutation and adverse pregnancy outcomes. Methods: This study is an analysis of a prospective observational study of the frequency of placenta-mediated complications of factor V Leiden mutation carriers. We compared pregnancy outcomes of 11 women with a heterozygous form of the factor V Leiden mutation with 41 women of a control group. Results: All pregnancies ended with delivery of a living infant. None of the 52 pregnancies were complicated by venous thromboembolism. There were a few significant differences regarding placenta-mediated complications. The gestational age at delivery showed small significant differences. There was a significant difference in the birth weight deviation in percentage between FVL carriers and controls. The incidence of blood loss exceeding $1000 \mathrm{ml}$ was higher in the control group. Conclusions: Carriership of the factor $\mathrm{V}$ Leiden mutation did not affect the incidence of preeclampsia. Adverse pregnancy outcomes such as placental abruption were rare. Eclampsia, intrauterine fetal death and venous thromboembolism did not occur. Our results provide evidence that the maternal heterozygous FVL mutation did not increase the risk of an adverse pregnancy outcome.

Key words: Pregnancy; Thrombophilia; Factor V Leiden; Venous thromboembolism; Adverse pregnancy outcome; Preeclampsia; IUGR, IUFD; Placental abruption

\section{Introduction}

During pregnancy the gentle haemostatic balance shifts towards enhanced coagulation, resulting in an increased risk of venous thromboembolism. Pulmonary embolism is the main cause of maternal mortality in developed countries (3). As a result of influencing placental perfusion, thrombotic processes have been described as an important pathogenetic factor in some severe obstetric conditions (such as preeclampsia, intrauterine growth restriction (IUGR) and placental abruption).

Thrombotic events have also been found in fetal circulation. Both congenital and acquired thrombophilias are implicated in pathophysiological processes associated with thrombotic damage of the placenta as well as with an increased risk of venous thromboembolism (VTE) (Tab. 1).

Activated factor V (FVa) acts as a cofactor to activated factor X (FXa) in the conversion of prothrombin. The procoagulant function of FVa is down-regulated by the serine protease activated protein C (APC) for haemostatic maintenance. The activation of protein $\mathrm{C}$ begins on the surface of endothelial cells through the thrombin-thrombomodulin complex.
The factor V Leiden mutation is the most common thrombophilia and its prevalence of heterozygosity in Caucasian

Tab. 1: Incidence of hereditary thrombophilia in the general population and in patients with venous thromboembolism (VTE).

\begin{tabular}{|l|c|c|}
\hline & \multicolumn{2}{|c|}{ Frequency (\%) } \\
\hline & $\begin{array}{c}\text { in the general } \\
\text { population }\end{array}$ & $\begin{array}{c}\text { in patients } \\
\text { with VTE }\end{array}$ \\
\hline $\begin{array}{l}\text { Factor V Leiden } \\
\text { (heterozygous) }\end{array}$ & $3.60-6.00$ & 21 \\
\hline $\begin{array}{l}\text { Factor V Leiden } \\
\text { (homozygous) }\end{array}$ & $0.10-0.02$ & 2 \\
\hline Protein C deficiency & $0.14-0.50$ & 3.2 \\
\hline Protein S deficiency & unknown & 2.2 \\
\hline $\begin{array}{l}\text { Antithrombin } \\
\text { deficiency (type I) }\end{array}$ & $0.02-0.17$ & 1.1 \\
\hline $\begin{array}{l}\text { Prothrombin G20210A } \\
\text { mutation }\end{array}$ & $1-4$ & $2-8$ \\
\hline Hyperhomocysteinemia & $5-10$ & $10-25$ \\
\hline
\end{tabular}

Information obtained from Ref. 2. 
population varies between $2-15 \%$. The highest prevalence is in Northern Europe and in the Middle East (37).

Activated protein C resistance (APC resistance) was first described by Dahlbäck in 1993 (8). More than 95\% of APC resistance cases are due to a point mutation in the factor $\mathrm{V}$ gene known as the Leiden mutation (9). The molecular basis of this phenotype was identified as a single point mutation $\mathrm{G} \rightarrow \mathrm{A}$ in position 1691 , changing arginine $\left(\mathrm{Arg}^{506}\right)$ of factor $\mathrm{V}$ to glutamine (2). In 1998, two other rare factor $\mathrm{V}$ mutations were found: arginine ( $\mathrm{Arg}^{306}$ ) to glycine (FV Hong-Kong) or threonine (FV Cambridge) $(5,36)$. The mutated factor Va becomes resistant to proteolytic inactivation of activated protein $\mathrm{C}$. The rate of inactivation of the mutant factor $\mathrm{V}$ is diminished, resulting in a higher plasma level of thrombin. This rising thrombin production results in a predisposition to venous thromboembolism (VTE) (29). The risk of VTE associated with the factor V mutation is amplified by other risk factors (Tab. 2).

Tab. 2: Risk factors of deep venous thrombosis in pregnancy.

\begin{tabular}{|l|l|}
\hline Age & Malignancy \\
\hline Previous thrombosis & Antiphospholipid syndrome \\
\hline Immobilization & Myeloproliferative disorders \\
\hline Surgery & Venous stasis \\
\hline Trauma & Obesity \\
\hline Nephrotic syndrome & Sepsis \\
\hline
\end{tabular}

Preeclampsia, placental abruption, intrauterine growth restriction (IUGR) and intrauterine fetal death (IUFD) contribute to maternal and fetal morbidity and mortality.

Preeclampsia can be caused by poor placentation involving the spiral arteries and leads to inadequate uteroplacental flow. Between the 8th and 18th gestation week an altered trophoblast invasion of the spiral arterial walls appears. The result is a massive maternal inflammatory response (12). Placental changes characterized by superficial endovascular cytotrophoblast invasion in the spiral arteries and intervillous space are called placental vasculopathy. Placental apoptotic

Tab. 3: Risk factors of preeclampsia.

\begin{tabular}{|l|l|}
\hline Primipaternity & Chronic hypertension \\
\hline $\begin{array}{l}\text { Pregnancy after donor } \\
\text { insemination }\end{array}$ & Renal disease \\
\hline $\begin{array}{l}\text { Pregnancy after oocyte/ } \\
\text { embryo donation }\end{array}$ & $\begin{array}{l}\text { Obesity and insulin } \\
\text { resistance }\end{array}$ \\
\hline Extremes of maternal age & $\begin{array}{l}\text { Pregestational diabetes } \\
\text { mellitus }\end{array}$ \\
\hline Multifetal gestation & Maternal infections \\
\hline $\begin{array}{l}\text { Preeclampsia in previous } \\
\text { pregnancy }\end{array}$ & $\begin{array}{l}\text { Hydropic degeneration } \\
\text { of the placenta }\end{array}$ \\
\hline
\end{tabular}

Information obtained from Ref. 13. and necrotic debris reaches maternal circulation, resulting in endothelial damage and activation of blood coagulation (25). Some studies suggest that poor placentation provokes maternal circulation, which compensates by increasing the blood pressure (15). The risk factors of preeclampsia are described in Table 3.

Placental abruption is a serious obstetric condition associated with high perinatal mortality and high maternal morbidity and mortality. Known risk factors are shown in Table 4.

Tab. 4: Risk factors for placental abruption.

\begin{tabular}{|l|l|}
\hline Uterus trauma & Cigarette smoking \\
\hline Hypertension & Advanced maternal age \\
\hline Fetal growth restriction & Multiparity \\
\hline
\end{tabular}

Information obtained from Ref. 14.

Abruption of the placenta is characterized as the separation of the implanted placenta by hemorrhage into the decidua basalis. This process starts with uterine vasospasm followed by relaxation and consequently venous stasis. The arterioles rupture and separation of the placenta occur. Placental biopsies after abruption show the same abnormal vascular structures as in preeclampsia (33).

Intrauterine growth restriction (IUGR) has serious consequences for neonates. IUGR is associated with an increased risk of premature birth, increased morbidity, including necrotizing enterocolitis, hypoxic brain injury, retinopathy of prematurity, and, later in life, obesity, diabetes and ischaemic heart diseases. The placenta is the interface between fetal and maternal circulation and plays an essential role in supporting normal fetal growth. Pathology affecting the placenta is responsible for the majority of IUGR (7).

The relationship between intrauterine fetal death (IUFD) and the factor $\mathrm{V}$ mutation is debatable. It is unlikely that the factor $\mathrm{V}$ Leiden mutation can cause early miscarriage by increasing blood coagulation because fetal nutrition is, up to the 10th week of pregnancy, mainly histiotrophic, with the maternal intraplacental circulation being fully established after the third month of gestation (4). Numerous studies have been published and the results are controversial due to the between-study heterogenity.

\section{Material and Methods}

The aim of this prospective study was to find the association between the factor $\mathrm{V}$ Leiden mutation and adverse pregnancy outcomes such as preeclampsia, eclampsia, intrauterine growth restriction (IUGR), intrauterine fetal death (IUFD), prematurity, placental abruption and venous thromboembolism. This study is an analysis of a prospective observational study of the frequency of placenta-mediated complications of factor V Leiden mutation carriers. Patients 
were enrolled in this study between October 2006 and September 2009 and were followed up in our antenatal clinic. All subjects gave informed consent in accordance with the principles of the Declaration of Helsinki. Our study included 52 women. The diagnosis of the factor V Leiden mutation was made in the pre-conception period. The heterozygous factor $\mathrm{V}$ Leiden mutation was confirmed in 11 women by a polymerase chain reaction (PCR). Negative results were obtained in 41 women. All women in the study population were Caucasian. In this study we had only women with a singleton pregnancy and a history of one unexplained abortion in the first trimester before thrombophilia screening. Other inclusion criteria were the absence of venous thromboembolism before pregnancy, presence of no other thrombophilic abnormalities and a negative family history for venous thromboembolism. Women with BMI $>40$, hepatopathy and nephropathy were excluded. We observed these women from the 10th-15th week of pregnancy until their delivery. Five women with the factor V Leiden mutation were treated during pregnancy with a prophylactic dose of Nadroparin. The factor V Leiden carriers were compared with controls in terms of gestational age at delivery, preeclampsia, eclampsia, intrauterine fetal death, intrauterine growth restriction, placental abruption, blood loss at delivery, frequency of venous thromboembolism and superficial thrombophlebitis. The paired t-test was used for statistical evaluation.

\section{Results}

The median age at the time of enrollment of the 11 women with heterozygous factor V Leiden was 29 years (range 19-34 years). None of our women experienced venous thromboembolism before their pregnancy. The median age of the 41 controls was 28 years (range 20-34 years). None of the controls had a history of thrombosis. Data for pregnancy outcomes in patients and controls are shown in Table 5. All pregnancies ended with delivery of a living infant. None of

Tab. 5: Pregnancy outcome in women with heterozygous factor V Leiden and controls.

\begin{tabular}{|l|c|c|}
\hline & Patients & Controls \\
\hline Number of patients & 11 & 41 \\
\hline Viable infants $(\% *)$ & $11(100)$ & $41(100)$ \\
\hline IUFD $(\% *)$ & 0 & 0 \\
\hline IUGR $(\% *)$ & $3(27.3)$ & $4(9.7)$ \\
\hline Preeclampsia $(\% *)$ & $1(9.1)$ & $6(14.6)$ \\
\hline Eclampsia $(\% *)$ & 0 & 0 \\
\hline Birth before 37th week (\%*) & $1(9.1)$ & $7(17.1)$ \\
\hline Placental abruption $(\% *)$ & $1(9.1)$ & 0 \\
\hline Venous thromboembolism $(\% *)$ & 0 & 0 \\
\hline Vaginal delivery $(\% *)$ & $3(27.3)$ & $25(60.9)$ \\
\hline Caesarean section $(\% *)$ & $8(72.7)$ & $16(39.1)$ \\
\hline
\end{tabular}

* - percentage of pregnancies the 52 pregnancies were complicated by venous thromboembolism. Thromboprophylaxis and compression stockings which may have prevented some VTE (five women with the factor V Leiden mutation, were treated with Nadroparin and one had compression stockings because of varicose veins of lower extremities) were provided more to the factor $\mathrm{V}$ Leiden mutation carriers than to the controls.

There were significant differences regarding placentamediated complications. The gestational age at delivery showed significant differences $(\mathrm{p}<0.05)$. There was a significant difference in the birth weight deviation between FVL carriers and controls $(\mathrm{p}<0.05)$. The total blood loss at delivery defined by measuring and estimating was lower in the factor V Leiden carriers, but the difference was not significant.

The incidence of blood loss exceeding $1000 \mathrm{ml}$ was higher in the control group $(\mathrm{p}<0.05)$. Table 6 shows the comparison of total blood loss during delivery between the factor V Leiden mutation carriers and controls.

Tab. 6: Comparison of total blood loss in carriers and controls during delivery.

\begin{tabular}{|l|c|c|}
\hline & \multicolumn{2}{|c|}{ Number of } \\
\hline Blood loss $(\mathrm{ml})$ & patients $(\% *)$ & controls $(\% *)$ \\
\hline$>1000$ & 0 & $2(4.8)$ \\
\hline $600-1000$ & $3(27.3)$ & $11(26.8)$ \\
\hline$<600$ & $8(72.7)$ & $28(68.4)$ \\
\hline
\end{tabular}

* - percentage of pregnancies

\section{Discussion}

There is evidence showing that women with the factor $\mathrm{V}$ Leiden mutation can be at an increased risk of several severe obstetric complications.

Maternal thrombophilia together with natural haemostatic changes during pregnancy shift the gentle balance towards thrombotic changes in the placenta, resulting in inadequate fetomaternal circulation and leading to decreased placental perfusion (25). Intrauterine fetal growth restriction has been defined as a birth weight below the 5 th percentile for the gestational age. A higher incidence of IUGR in our study group confirms the results of several studies showing the relationship between placental pathology and maternal thrombophilia $(1,17)$. The etiology of IUGR is multifactorial and thrombophilia can play an additional role.

On the other hand, several studies have found no significant difference in birth weight deviation between FVL carriers and controls, thus indicating no elevated risk for $\operatorname{IUGR}(6,11,18,35)$. A possible association may exist between IUGR and the factor V Leiden mutation but the data obtained from various studies are not homogenous.

Miscarriage is defined as a termination of the pregnancy in the first and second trimester and stillbirth as a pregnancy loss occurring after 22nd week of pregnancy. In 1998, 
Triplett and Harris identified a correlation between recurrent miscarriages and the antiphospholipid antibodies syndrome, while in 1996 Sanson suggested a connection between fetal loss and PC, PS and AT deficiency $(27,34)$. Since then, a number of studies have been carried out which tried to find an association between thrombophilia and abortion/stillbirth. Fetal chromosome defects have been suggested to be the most common reason for sporadic miscarriage, accounting for $50 \%$ of all miscarriages (30). The maternal factors seem to be more and more important in pregnancy outcomes (31). It is now widely accepted that recurrent miscarriage has a multifactorial etiology, including prothrombotic state, structural uterine abnormalities, endocrinological defects, infections, immune dysfunctions or endometrial responsiveness. A meta-analysis which included 31 studies regarding thrombophilic disorders and fetal loss showed that the factor V Leiden mutation was associated with early and late recurrent fetal loss and late non-recurrent fetal loss (24). Preeclampsia affects $5 \%$ of singleton pregnancies. Its etiology is still unclear. It is characterized by an abnormal vascular response to placentation associated with increased systematic vascular resistance, enhanced platelet aggregation, activation of the coagulation system and endothelial cell dysfunction (28). Clinically, preeclampsia was defined as blood pressure higher than $160 / 110 \mathrm{mmHg}$, urinary protein excretion greater than $5 \mathrm{~g} / 24 \mathrm{~h}$ and a platelet count of less than $100000 / \mathrm{mm}^{3}$. Some studies have shown an association between thrombophilia and an early onset of severe preeclampsia but not mild or term preeclampsia. According to these studies preeclampsia is significantly associated with the factor $\mathrm{V}$ Leiden mutation. There is also an increased tendency for maternal complications such as disseminated intravascular coagulation (DIC) and acute renal failure (26). In our study, the prevalence of preeclampsia was not higher in FVL carriers than in controls and was in accordance with the five largest case-control studies and three prospective studies $(6,10,11,14,16,19,20,32)$.

Current evidence shows that there are similar vasculopathic changes in preeclampsia, IUGR, fetal loss and placental abruption. The etiology of placental abruption is multifactorial and thrombophilia can play a role.

Placental abruption was defined by clinical criteria (vaginal bleeding, uterine tenderness and fetal distress). In our small study there occurred only one placental abruption. In two of the three largest retrospective studies and two prospective studies, no significant association was found between the factor $\mathrm{V}$ Leiden mutation and placental abruption $(11,13,16,22,23)$.

Some authors suggest that the factor V Leiden carriers have less blood during delivery compared with non-carriers (16). Our study confirmed this suggestion.

\section{Conclusions}

Carriership of the factor V Leiden mutation in our study did not affect the incidence of preeclampsia. Adverse preg- nancy outcomes such as placental abruption were rare. Eclampsia, intrauterine fetal death and venous thromboembolism did not occur. Thromboprophylaxis may have influenced the prevalence of VTE. The incidence of blood loss during delivery exceeding $1000 \mathrm{ml}$ was significantly higher in the control group. However, our small study confirmed some results of the largest studies. In patients with negative personal or family histories for thromboembolism, the heterozygous factor $\mathrm{V}$ Leiden mutation is associated with a lower risk of thromboembolism in pregnancy. Therefore, neither the screening of all pregnant women nor the treatment of the low risk carriers is recommended. In cases with a thrombophilic etiology close collaboration between obstetricians and haematologists is the main key to ensuring a successful pregnancy.

\section{Acknowledgements}

The authors would like to thank The National Haemophilia Centre at the Institute of Haematology and Blood Transfusion, University Hospital, Bratislava, Slovakia.

\section{References}

1. Arias F, Romero R, Joist H, Kraus FT. Thrombophilia: a mechanism of disease in women with adverse pregnancy outcome and thrombotic lesions in the placenta. J Matern Fetal Med 1998; 7:227-286.

2. Bertina RM, Koeleman BPC, Koster T, Rosendaal FR, Dirven RJ, de Ronde H et al. Mutation in blood coagulation factor $\mathrm{V}$ associated with resistance to activated protein C. Nature 1994; 369:64-67.

3. Bourjeily G, Paidas M, Khalil H, Rosene-Montella K, Rodger M. Pulmonary embolism during pregnancy. Lancer 2009; 375(suppl 9713):500-512.

4. Burton GJ, Watson AL, Hempstock J, Skepper JN, Jauniaux E. Uterine glands provide histiotrophic nutrition for the human fetus during the first trimester of pregnancy. J Clin Endocrinol Metab 2002; 87:2954-2959.

5. Chan WP, Lee CK, Kwong YL, Lam CK, Liang R. A Novel Mutation of Arg ${ }^{306}$ of Factor V Gene in Hong Kong Chinese. Blood 1998; 91(suppl 4):1135-1139.

6. Clark P, Walker ID, Govan L, Wu O, Greer IA. The GOAL study: a prospective examination of the impact of factor $\mathrm{V}$ Leiden and $\mathrm{ABO}(\mathrm{H})$ blood groups on hemorrhagic an thrombotic pregnancy outcomes. Br J Haematol 2007; 140:236-240.

7. Cox P, Marton T. Pathological assessment of intrauterine growth restriction. Best Pract Res Clin Obstet Gynaecol 2009; 23(6):751-764.

8. Dahlbäck B, Carlsson M, Svensson PJ. Familial thrombophilia due to a previously unrecognized mechanism characterized by poor anticoagulant response to activated protein C: prediction of a cofactor to activated protein C. Proc Natl Acad Sci USA 1993; 90:1004-1008.

9. Dahlbäck B, Carlsson M, Svensson PJ. Familial thrombophilia due to a previously unrecognized mechanism characterized by poor anticoagulant response to activated protein C: prediction of a cofactor to activated protein C. Proc Natl Acad Sci USA 1993; 90:1004-1008.

10. De Groot CJM, Bloemenkamp KWM, Duvenkot EJ, Helmerhorst FM, Bertina RM, Vander Meer F et al. Preeclampsia and genetic risk factors for thrombosis: A case-control study. Am J Obstet Gynecol 1999; 181:975-980.

11. Dizon-Townson D, Miller C, Sibai B, Spong CY, Thom E, Wendel JrG. The relationship of the factor V Leiden mutation and pregnancy outcomes for mother and fetus. Obstet Gynecol 2005; 106:517-524.

12. Faas MM, Schuiling GA. Preeclampsia and the inflammatory response. Eur J Obstet Gynecol Reprod Biol 2001; 95:213-217.

13. Jääskeläinen E, Tiovonen S, Romppanen EL, Helisalmi S, Keski-Nisula L, Punnonen K, Heinonen S. M385T polymorphism in the factor $\mathrm{V}$ gene, but not Leiden mutation, is associated with placental abruption in Finnish women. Placenta 2004; 25:730-734.

14. Kim YJ, Williamson RA, Murray JC, Andrews J, Pietscher JJ et al. Genetic susceptibility to preeclampsia: Roles of cytosine-to-thymine substitution at nucleotide 677 of the gene for methylenetetrahydrofolate reductase, 68-base pair insertion at nucleotide 844 of the gene for cystathionine $\beta$-synthase, and factor V Leiden mutation. Am J Obstet Gynecol 2001; 184:1211-1217.

15. Lindheimer MD, Taler SJ, Cunningham FG. Hypertension in pregnancy. J Am Soc Hypertens 2008; 2(6):484-494.

16. Lindquist P, Dahlbäck B, Maršál K. Thrombotic risk during pregnancy: A population study. Obstet Gynecol 1999; 94:595-599. 
17. Many A, Schreiber L, Rosner S, Lessing JB, Eldor A, Kupferminc MJ. Pathologic features of the placenta in women with severe pregnancy complications and thrombophilia. Obstet Gynecol 2001; 98:1041-1044.

18. McCowan LME, Craigie S, Taylor RS, Ward Ch, McLintock C, North RA. In herited thrombophilias are not increased in "idiopathic" small-for-gestational-age pregnancies. Am J Obstet Gynecol 2003; 188(4):981-985.

19. Mello G, Parretti E, Marozio L, Pizzi C, Lojacono A, Frusca T et al. Thrombophilia is significantly associated with severe preeclampsia. Hypertension 2005; $46: 1270-1274$

20. O'Shaughnessy KM, Fu B, Ferraro F, Lewis I, Downing S, Morris NH. Factor V Leiden and thermolabile methylenetetrahydrofolate reductase gene variants in an East Anglian preeclampsia cohort. Hypertension 1999; 33:1338-1341.

21. Pabinger I, Vormittag R. Thrombophilia and pregnancy outcome. J Thromb Haemost 2005; 3:1603-1610

22. Procházka M, Happach C, Maršál K, Dahlbäck B, Lindquist PG. Factor V Leiden in pregnancies complicated by placental abruption. BJOG 2003; 110:462-466.

23. Procházka M, Lubušký M, Slavík L, Hrachovec P, Zielina P, Kudela M, Lindquist PG. Frequency of selected thrombophilias in women with placental abruption. Aust N Z J Obstet Gynaecol 2007; 47(4):297-301.

24. Ray E, Kahn SR, David M, Shrier I. Thrombophilic disorders and fetal loss: a meta-analysis. Lancet 2003; 361:901-908.

25. Redman CWG, Sargent IL. Preeclampsia, the Placenta and the Maternal Systematic Inflammatory Response - A Review. Placenta 2003; 24(suppl A):S21-S27.

26. Robertson L, Wu O, Langhorne P, Twaddle S, Clark P, Lowe GD, Walker ID, Greaves M, Brenkel I, Regan L et al. Thrombophilia in pregnancy: a systematic review. Br J Haematol 2006; 132:171-196.

27. Sanson BJ, Friedrich PW, Simioni P. The risk of abortion and stillbirth in antit- hrombin-, protein C-, and protein S-deficient women. Thromb Haemost 1996 75:387-388.

28. Sibai B, Dekker G, Kupferminc M. Pre-eclampsia. Lancet 2005; 365:785-799.

29. Spina V, Aleandri V, Morini F. The impact of Factor V Leiden mutation on pregnancy. Hum Reprod Update 2000; 6(suppl 3):301-306.

30. Stephenson MD, Awartani KA, Robinson WP. Cytogenetic analysis of miscarriages from couples with recurrent miscarriage: a case-control study. Hum Reprod 2002; 17:446-451.

31. Sullivan EA, Silver RM, LaCoursiere DY, Porter TF, Branch DW. Recurrent fetal aneuploidy and recurrent miscarriage. Obstet Gynecol 2004; 104:784-788.

32. The GOPEC Consortium. Disentangling fetal and maternal susceptibility for preeclampsia: A British multicenter candidate-gene study. Am J Hum Genet 2005; 77:127-131.

33. Tikkanen M, Nuutila M, Hiilesmaa V, Paavonen J, Ylikorkala O. Clinical presentation and risk factors of placental abruption. Acta Obstet Gynecol Scand 2006; 85(6):700-705.

34. Triplett DA, Harris EN. Antiphospholipid antibodies and reproduction. Am J Reprod Immunol 1989; 21:123-131.

35. Verspyck E, Borg JY, leCam-Duchez V, Goffinet F, Degré S, Fournet P. Thrombophilia and fetal growth restriction. Eur J Obstet Gynecol Reprod Biol 2004; 113:36-40.

36. Williamson D, Brown K, Luddington R, Baglin C, Baglin T. Factor V Cambridge: a new mutation $(\mathrm{Arg} 306 \rightarrow \mathrm{Thr})$ associated with resistance to activated protein $\mathrm{C}$. Blood 1998; 91:1140-1144.

37. Zivelin A, Mor-Cohen R, Kovalsky V, Kornbrot N, Conrad J, Peyvandi F et al. Prothrombin $20210 \mathrm{G}>\mathrm{A}$ is ancestral prothrombotic mutation that occurred in white approximately 24,000 years ago. Blood 2006; 107:4666-4668.

Received: 08/04/2010

Accepted in revised form: 23/06/2011

\section{Corresponding author:}

Lubica Hammerová, MD, 1st Department of Gynaecology and Obstetrics, Faculty of Medicine, Comenius University, Antolská 11,85107 Bratislava, Slovakia; e-mail: hammerova@gmail.com 